University of the District of Columbia School of Law

Digital Commons @ UDC Law

\title{
Vicarious Trauma and Ethical Obligations for Attorneys Representing Immigrant Clients: A Call to Build Resilience Among the Immigration Bar
}

Hannah C. Cartwright

Lindsay M. Harris

Liana M. Montecinos

Anam Rahman

Follow this and additional works at: https://digitalcommons.law.udc.edu/fac_journal_articles

Part of the Immigration Law Commons, and the International Humanitarian Law Commons 


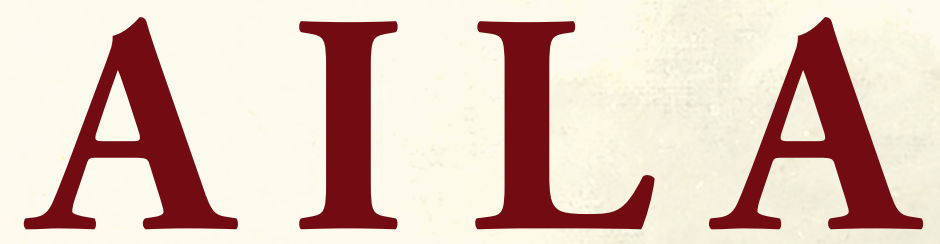

\section{Law Journal}

A Publication of the American Immigration Lawyers Association

Shoba Sivaprasad Wadhia

Editor-in-Chief

Volume 2, Number 1, April 2020

Letter from the Editor-in-Chief

Shoba Sivaprasad Wadhia.

\section{Enforcing/Protection}

Arguing Against Chevron Deference in Asylum and Withholding of Removal Cases Maureen A. Sweeniej

\section{Vicarious Trauma and Ethical Obligations for Attorneys Representing} Immigrant Clients

A Call to Build Resilience Among the Immigration Bar

Hannah C. Cartwright, Lindsay M. Harris, Liana M. Montecinos, and Anam Rahman

The Tax Consequences of Expatriating from the United States

Patrick J. McCormick

\section{Fake Problems with Faulty Solutions}

Why a Physical Barrier Is Not a Viable Answer to Trump's Purported "Crisis" at the

Border

Heather Adamick

2019 Visalaw.ai Case Management Survey Report

Greg Siskind 


\section{A I L A \\ Law Journal}

Volume 2, Number 1, April 2020

5 Letter from the Editor-in-Chief

Shoba Sivaprasad Wadhia

7 Enforcing/Protection

Arguing Against Chevron Deference in Asylum and Withholding of

Removal Cases

Maureen A. Sweeney

23 Vicarious Trauma and Ethical Obligations for Attorneys Representing Immigrant Clients

A Call to Build Resilience Among the Immigration Bar

Hannah C. Cartwright, Lindsay M. Harris, Liana M. Montecinos, and

Anam Rahman

41 The Tax Consequences of Expatriating from the United States

Patrick J. McCormick

51 Fake Problems with Faulty Solutions

Why a Physical Barrier Is Not a Viable Answer to Trump's Purported

"Crisis" at the Border

Heather Adamick

732019 Visalaw.ai Case Management Survey Report

Greg Siskind 


\section{EDITOR-IN-CHIEF}

\section{Shoba Sivaprasad Wadhia}

Samuel Weiss Faculty Scholar and Clinical Professor of Law, Founding Director of the

Center for Immigrants' Rights Clinic, Penn State Law in University Park

\section{EDITOR}

Danielle M. Polen

Director, Publications and Online Resources, AILA

\section{EDITOR EMERITUS}

Stephen H. Legomsky

John S. Lehmann University Professor Emeritus, Washington University Law in St. Louis

\section{BOARD OF EDITORS}

\section{Jim Alexander}

Managing Shareholder, Maggio Kattar Nahajzer + Alexander, PC

Dree K. Collopy

Partner, Benach Collopy, LLP

Kehrela Hodkinson

Principal, Hodkinson Law Group

\section{Geoffrey A. Hoffman}

Director, University of Houston Law Center Immigration Clinic, Clinical Professor of Law, University of Houston Law Center

\section{Matthew Hoppock}

Owner \& Principal, Hoppock Law Firm

Mahsa Khanbabai

Owner, Khanbabai Immigration Law

Cyrus D. Mehta

Founder \& Managing Partner, Cyrus D. Mehta \& Partners, PLLC (CDMP)

\section{Angelo A. Paparelli}

Partner, Seyfarth Shaw, LLP

Thomas K. Ragland

Member, Clark Hill, PLC

Craig R. Shagin

Member, The Shagin Law Group, LLC,

Adjunct Professor of Law, Widener Commonwealth Law School

\section{Rebecca Sharpless}

Professor, University of Miami School of Law

William A. Stock

Founding Member \& Partner, Klasko Immigration Law Partners, LLP,

AILA Past President

\section{Becki Young}

Co-Founder, Grossman Young \& Hammond, LLC 
AILA LAW JOURNAL is published two times per year by Full Court Press, a Fastcase, Inc., imprint. Individual issues may be purchased for $\$ 60.00$, or subscriptions for $\$ 99.00$ a year. Discounts are available for AILA members and Fastcase legal research users. Copyright 2020 American Immigration Lawyers Association. No part of this journal may be reproduced in any form-by microfilm, xerography, or otherwise - or incorporated into any information retrieval system without the written permission of the copyright owner: American Immigration Lawyers Association, Suite 300, 1331 G Street, NW, Washington, DC 20005-3142, Phone: 202-507-7600, Fax: 202-783-7853.

\section{Publishing Staff}

Publisher: Morgan Morrissette Wright

Journal Designer: Sharon D. Ray

Cover Design: Morgan Morrissette Wright and Sharon D. Ray

The cover of this journal features a painting known as "The Sea" by French artist Jean Désiré Gustave Courbet. A leader of the Realist movement, Courbet is also remembered for his political content and activism. The image is provided courtesy of the Metropolitan Museum of Art under a CC0 1.0 Universal (CC0 1.0) Public Domain Dedication.

Cite this publication as:

AILA Law Journal (Full Court Press, Fastcase, Inc.)

Copyright (C) 2020 American Immigration Lawyers Association.

All Rights Reserved.

A Full Court Press, Fastcase, Inc., Publication

Editorial Office

711 D St. NW, Suite 200, Washington, DC 20004

https://www.fastcase.com/

POSTMASTER: Send address changes to AILA LAW JOURNAL, 711 D St. NW, Suite 200, Washington, DC 20004. 


\section{Disclaimer}

The articles featured in the AILA Law Journal do not necessarily represent the views of AILA or the publisher, nor should they be regarded as legal advice from the association or authors. This publication is designed to be accurate and authoritative, but neither the publisher nor the authors are rendering legal or other professional services in this publication. If legal or other expert advice is desired, retain the services of an appropriate professional.

Likewise, the articles and columns reflect only the present considerations and views of the authors and do not necessarily reflect those of the firms or organizations with which they are affiliated, any of the former or present clients of the authors, or their firms or organizations.

\section{Submissions}

Direct editorial inquires and send material for publication to:

ailalawjournal@aila.org

Material for publication is welcomed-articles, decisions, or other items of interest to attorneys, law firms, and organizations working in immigration law.

\section{Questions About This Publication?}

For questions about the Editorial Content appearing in these volumes or reprint, please contact:

Morgan Morrissette Wright, Publisher, Full Court Press at mwright@fastcase.com or at 202.999 .4878

For questions about Sales, or to reach Customer Service:

Customer Service

Available 8am-8pm Eastern Time

866.773.2782 (phone)

support@fastcase.com (email)

Sales

202.999.4777 (phone)

sales@fastcase.com (email) 


\title{
Vicarious Trauma and Ethical Obligations for Attorneys Representing Immigrant Clients
}

\author{
A Call to Build Resilience Among the \\ Immigration Bar
}

Hannah C. Cartwright, Lindsay M. Harris, Liana M. Montecinos, and Anam Rahman*

\begin{abstract}
This article analyzes the ethical obligations for attorneys representing immigrant clients and the consequences of vicarious trauma, compassion fatigue, and burnout for the immigration bar and immigrant clients. The authors identify barriers for immigration attorneys in preventing, recognizing, and responding to vicarious trauma in themselves and colleagues and suggest practical ways that the immigration bar can and should seek to build resilience.
\end{abstract}

Trauma is embedded in the practice of immigration law, especially for attorneys who represent clients seeking humanitarian and discretionary immigration relief. This article analyzes trauma within the practice of immigration law, the ethical obligations for attorneys representing immigrant clients under the ABA Model Rules of Professional Conduct, and the consequences of vicarious trauma among the immigration bar. The authors then identify barriers for immigration attorneys in preventing, recognizing, and responding to vicarious trauma and suggest practical ways that the immigration bar can build resilience.

\section{Trauma and Immigration Law}

Scholars from the fields of psychology and social work describe three potential periods of trauma for migrants: trauma suffered in the country of origin, trauma suffered during the migration journey, and trauma of relocating. ${ }^{1}$ This "triple trauma paradigm," however, does not necessarily acknowledge that being undocumented in the United States often also traumatizes clients, because this concept was originally theorized in the context of refugees who already possess status upon arrival. The theory also does not encompass the reality that many immigrants are vulnerable to additional traumas once in the United States, including criminal victimization. Nor does this theory acknowledge that the 
process of applying for relief before an immigration court or U.S. Citizenship and Immigration Services (USCIS) may in itself be an additional source of trauma once an individual has arrived in the United States or is forced to start the process through the Migrant Protection Protocols (MPP) in Mexico.

Given the layers of trauma that immigrant clients may be exposed to before even entering law offices, it is no surprise that many immigration attorneys-like others who find themselves in helping professions, such as public defenders, civil legal aid attorneys, and family law attorneys-find themselves regularly exposed to trauma as a part of their legal practices. This article places special emphasis on the experience of immigration attorneys engaged in removal defense and affirmative practices that involve applying for humanitarian relief such as asylum, withholding of removal, protection under the Convention against Torture (CAT), discretionary waivers, and relief under the Violence Against Women's Act (VAWA), including self-petitions and U-visas. All of these forms of relief require "the lawyer to prepare the client to tell the story of their pain, to tell the story of the torture they have experienced.... Thus, the trauma becomes the centerpiece of the representation and [requires attorneys to] engage it as a critical mass of legal data and evidence." ${ }^{2}$ In other words, the trauma that the client has experienced becomes integral to the attorney-client representation itself, as does the evidence of the trauma that immigration attorneys must review and present to sustain a client's burden of proof. This wide range of evidence may include gruesome photos, death certificates, police reports, and newspaper articles documenting harm; forensic psychological and medical reports; and international reports on human rights abuses.

Attorneys and legal staff describe the "impact" of confronting these client narratives and documentary evidence in a variety of terms, in part because the legal profession has not adequately trained attorneys to recognize the spectrum of negative impact that working with traumatized populations may bring to the surface. Given this professional limitation, this article relies on the definitions delineated in the social work profession in order to better address the consequences and professional responsibility that attorneys have in addressing the impact of this work.

Colloquially, the term "burnout" is often used. However, "professional burnout" describes a specific phenomenon in which a professional's personal experiences, combined with the negative cumulative effects of providing services to clients over a particular time and organizational dynamics of the advocate's employment environment, result in "emotional exhaustion, depersonalization, and reduced sense of personal accomplishment." ${ }^{3}$ In contrast, "secondary trauma" or "secondary traumatic stress" results from engaging in an empathetic relationship with an individual suffering from a traumatic experience and bearing witness to the intense or horrific experiences of that particular person's trauma. "Compassion fatigue" is best described as a state in which an advocate-most often a professional engaged in a helping profession such 
as psychology, social work, or legal aid lawyering-is experiencing symptoms of both burnout and secondary trauma. ${ }^{5}$

While all three-professional burnout, secondary trauma, and compassion fatigue-are consequences that attorneys may attempt to avoid in order to find sustainability in their professional lives, it is vicarious trauma that is most concerning and risky from a professional and ethical perspective. Vicarious trauma describes "the resulting cognitive shifts in beliefs and thinking that occur ... in direct practice with victims of trauma." 6 These changes in beliefs and thinking include alterations in "one's sense of self" as well as changes around fundamental issues such as "safety, trust, and control; and changes in spiritual beliefs." "This shift may manifest itself in a variety of negative trauma exposure responses, such as the minimization of others' experiences, inability to embrace complexity, diminished creativity, avoidance and inability to listen, inability to empathize, and an inflated sense of importance related to one's work as well as corresponding feelings of helplessness - any one of which may cripple an attorney's ability to establish trusting relationships with clients and advocate zealously on their behalf. ${ }^{8}$ Additionally, other trauma exposure responses such as cynicism, anger, fear, guilt, hypervigilance, intrusive images, physical ailments and somatic symptoms ranging from headaches and stomachaches to more severe ailments, substance abuse, and chronic exhaustion may not only affect an attorney's representation but also their health and wellness. ${ }^{9}$ These negative trauma exposure responses may affect how attorneys think, react, and practice, thereby putting at risk the fundamental ethical obligations that attorneys have to immigrant clients.

\section{Ethical Obligations of Immigration Attorneys}

Many of the symptoms of vicarious trauma described above affect the most fundamental aspects of the attorney-client relationship. Thus, unabated negative trauma exposure responses may lead to serious ethical issues. This section will cover the ethical obligations of immigration attorneys and ethical issues that arise with attorneys experiencing vicarious trauma.

For immigration attorneys, there is no single comprehensive authority for guidance on ethics. Although USCIS and Executive Office for Immigration Review (EOIR) regulations address the discipline of attorneys and non-attorney representatives, they do not provide detailed guidance on actual ethical issues faced by immigration lawyers. Instead, the ethics rules applicable to immigration lawyers are the rules of ethics for the state in which the lawyer is licensed to practice. For purposes of this article, however, references will be made to the Model Rules of Professional Conduct (Model Rules) drafted by the American Bar Association (ABA). The majority of states, including the District of Columbia, have adopted the Model Rules either completely or with relatively minor changes. 


\section{Competent Representation (Model Rule 1.1)}

A lawyer shall provide competent representation to a client. Competent representation requires the legal knowledge, skill, thoroughness and preparation reasonably necessary for the representation.

Although Model Rule 1.1 may seem elementary and simply worded in its requirement of competence, maintaining the level of knowledge and thoroughness necessary to represent immigration clients is an ever-increasing challenge. Especially now, with immigration law and policy changing almost daily, it is critical that attorneys research and study the law to keep abreast of changes that may affect a client's case. The ethical duty of competence requires thoroughness and adequate preparation in handling a client matter, particularly considering the drastic consequences that removal or visa refusal have on our clients and families. Because the stakes are so high in immigration cases, immigration attorneys are under more pressure than ever to competently represent their clients.

For an attorney suffering from vicarious trauma, she must be especially mindful about whether she is able to provide competent representation as required under Model Rule 1.1. Indeed, even a knowledgeable, experienced, and dedicated immigration lawyer may be unable to provide competent representation if she is suffering from symptoms of vicarious trauma or burnout. For example, an attorney feeling overwhelmed, disoriented, and hopeless may be inclined to procrastinate until the last moment and then rush through the work or put off the required preparation altogether. Whether the lapse of competent representation is checking off the wrong box on an employment authorization renewal or failing to include crucially obvious supporting documentation, the prejudice to the client may be dire. Thus, prior to accepting representation, an attorney must consider whether she is are capable of providing competent representation and also must self-monitor themselves throughout representation to ensure that they are maintaining the required level of competence.

Moreover, as others have recognized, the duty to provide competent representation to clients who have experienced trauma includes an obligation to understand trauma and its impact. ${ }^{10}$ Knowledge and skills in working with clients who have survived trauma as well as in managing one's own trauma exposure responses are necessary to avoid retraumatizing clients. Without such knowledge and skills, attorneys are impeded from undertaking basic critical tasks such as interviewing a trauma survivor, counseling a victim on available options, gathering facts and evidence in support of a claim, and presenting a victim's testimony. ${ }^{11}$ As such, reasonably necessary thoroughness and preparation may very well include consulting with a mental health professional to improve upon the attorney's knowledge and skills working with survivors of torture and also to aid with any specific trauma-based symptoms the attorney may be experiencing. In addition, competent representation requires that immigration attorneys and staff be attentive and culturally competent in their 
work in order to build trust with clients from diverse backgrounds, many of whom may have differing cultural experiences, religious beliefs, race, class, and gender from the attorneys representing them. ${ }^{12}$

\section{Diligent Representation (Model Rule 1.3)}

A lawyer shall act with reasonable diligence and promptness in representing a client.

\section{Communication (Model Rule 1.4)}

(a) A lawyer shall:

(1) promptly inform the client of any decision or circumstance with respect to which the client's informed consent, as defined in Rule $1.0(\mathrm{e})$, is required by these Rules;

(2) reasonably consult with the client about the means by which the client's objectives are to be accomplished;

(3) keep the client reasonably informed about the status of the matter;

(4) promptly comply with reasonable requests for information; and

(5) consult with the client about any relevant limitation on the lawyer's conduct when the lawyer knows that the client expects assistance not permitted by the Rules of Professional Conduct or other law.

(b) A lawyer shall explain a matter to the extent reasonably necessary to permit the client to make informed decisions regarding the representation.

Often associated with the concept of "zealous representation," reasonable diligence and promptness require that an attorney do whatever must be done to provide the agreed upon legal services without any unjustified delay. And, just as with a lack of competence, an attorney's failure to handle a matter with reasonable diligence and promptness may result in dire consequences for an immigrant client. For example, an attorney's failure to file an adjustment of status application prior to expiration of the client's status could result in denial of the application and placement in removal proceedings. Similarly, an attorney's failure to file an application for asylum within one year of a client's arrival may bar the client from obtaining asylum relief altogether. Beyond potentially irreparable injury to the client, an attorney's lack of diligence and promptness could also cause the client to lose confidence in the attorney and erode the attorney-client relationship.

An attorney suffering from vicarious trauma may manifest symptoms that impair her ability to exercise reasonable diligence and promptness in a client's case. Comment 3 for Model Rule 1.3 notes how "[p]erhaps no professional shortcoming is more widely resented than procrastination." Avoidance, a symptom of vicarious trauma, can certainly lead to procrastination. For instance, an attorney who is triggered by a client's past sexual abuse due to the attorney's own past sexual abuse may procrastinate working on the client's case or not sufficiently delve into the facts of the prior abuse for the client's affidavit and testimony. Or an attorney who has been practicing for 
many years representing clients with similar claims might subconsciously or consciously minimize the harm a client suffered and fail to elicit all of the facts from the client. Not only could such avoidance result in the attorney's failure to uncover harm or experiences that could make a client eligible for a particular form of immigration relief, but also if a client testifies or offers evidence about previously undisclosed harm in immigration court, the omission could result in credibility challenges by the Department of Homeland Security. Additionally, an attorney's avoidance, inability to embrace complexity, and diminished creativity may also affect the ability of the attorney to conduct legal research, zealously advance articulate and creative legal arguments, and write complex legal briefs. In short, failure to combat or mitigate trauma exposure responses can result in weaker immigration cases, which may rise to the level of ineffective assistance of counsel.

Going hand-in-hand with Model Rule 1.3's ethical requirement for reasonable diligence and confidence, Model Rule 1.4 requires that an attorney keep her clients reasonably and promptly informed. This obligation includes the attorney's duty to inform a current or former client of the lawyer's material error. An attorney suffering from vicarious trauma might avoid the client's phone calls and not keep the client apprised about the status of the case, especially when the news involves denial of the benefit or relief sought. Additionally, in a practice area where communicating with clients often requires the use of interpreters or translators, working with family or community members as intermediaries, or even working with clients who are legally incompetent, ${ }^{13}$ an attorney's avoidance of client communication can seriously undermine the attorney-client relationship.

\section{Responsibilities of a Partner or Supervisor Lawyer}

(a) A partner in a law firm, and a lawyer who individually or together with other lawyers possesses comparable managerial authority in a law firm, shall make reasonable efforts to ensure that the firm has in effect measures giving reasonable assurance that all lawyers in the firm conform to the Rules of Professional Conduct.

Finally, the Model Rules address the responsibilities of attorneys serving in a supervisory capacity over other lawyers as well as legal staff who carry out legal work on behalf of an attorney, law firm, or organization. This rule lays out another guideline implicating the work of attorneys in group settings and suggests that attorneys serving as leaders and supervisors must ensure that firm culture and policies allow for proper training, recognition, and mitigation of negative trauma exposure responses in order to both prevent and respond to vicarious trauma among reporting staff.

This ethical responsibility is particularly challenging during a time when the entire immigration bar is negotiating negative trauma responses as well as constantly changing policies from the Trump administration that directly affect the practice. It is easy for vicarious traumatization to lead to a negative 
organizational culture and toxic workplaces. For example, practitioners often engage in the coping mechanism of minimizing the experiences of others around them because "we feel saturated to the point that we can't possibly let any more information in .... [W] e are literally at capacity." ${ }^{14}$ However, as author Laura van Dernoot Lipsky explains, when professionals engage in minimization in a workplace, there are consequences; if a colleague expresses irritation and anger, that colleague may be less approachable to others in a time of conflict and may make it difficult for the conflict to be resolved in a healthy manner. ${ }^{15}$ Minimization can also lead to competition for resources and an attitude of scarcity, particularly in a field where there is no right to counsel and a seemingly never-ending stream of clients in need of representation. ${ }^{16}$

The risk of vicarious trauma as a supervisory concern for firms and organizations can have very real practical consequences, including high employee turnover and consequently increased hours devoted to hiring, lower productivity, and lower morale. ${ }^{17}$ Unfortunately, in addition to loss of income for firms and financial resources for legal aid organizations, the result also directly impacts the quality of representation provided to clients due to the inexperience of new attorneys and support staff. Additionally, client representation is often inconsistent and interrupted due to attorney or staff departures, especially over the long course of non-detained immigration cases in jurisdictions where clients wait many months or years for immigration court hearings or USCIS office interviews. While some departures are unavoidable and even reflect natural attrition, the scale of attorney burnout in the immigration bar may lead to the opposite of trauma-informed care where firms and organizations are crippled by attorney departures and as such are not able to provide trauma-informed services in ways that create reasonable client expectations and build trust between staff and clients.

\section{The Barriers to Recognizing, Preventing, and Responding to Vicarious Trauma for Immigration Lawyers}

Barriers to recognizing, preventing, and responding to vicarious trauma emerge in law school and solidify in both private and nonprofit practice settings. Some of these barriers are the realities of immigration lawyering: high caseloads due to community needs and the need for firm revenue; tight deadlines before certain courts and asylum offices juxtaposed with incredibly lengthy deadlines with more backlogged courts and asylum offices, which make continuing long-term client relationships and managing case preparation a challenge; and a constantly changing legal landscape that generates feelings of constant crisis. Additionally, the heavy politicization of immigration makes it difficult for attorneys to "leave work at home" when immigration policies are constantly discussed on television, radio, and social media and among friends and family. 
However, beyond these practical and contextual barriers, a substantial barrier to recognizing, preventing, and responding to vicarious trauma stems from the foundations of the legal profession and corresponding legal culture. From the moment law students step inside the door of the law school, they are taught to "think like a lawyer." However, this mode of thinking has, at least historically, not been associated with being compassionate, being in touch with one's emotions, or acknowledging vulnerability to colleagues, supervisors, or clients. ${ }^{18}$ Instead, generations of attorneys have been applauded for their skills at compartmentalizing, pushing down emotions, and demonstrating their ability to persevere "in the trenches." Lawyers then reinforce these expectations with younger attorneys whom they mentor and train, perpetuating patterns of lawyer conduct and generational patterns of vicarious trauma in workplaces. Yet within this "stiff upper lip" culture, stories, like these below provided by the authors, are shared from attorney to attorney:

"I gasped for air until I woke up at approximately 3:00 A.M. I was in shock and terror, even minutes after I realized it was just a nightmare. I had seen the gang muffle a man's mouth and strap his feet and hands to a chair, rendering him immobile. I recognized the man as my brother. I could see what they were doing to him, but I was too far away to intervene. When I woke from the dream, my eyes were widened as I lunged, my body howling, but no sound came out of my mouth. This nightmare was an incident one of my asylum-seeking clients shared with me, but in my nightmare, it was happening to my brother. It was in this moment I realized that I needed to be more cognizant of signs of vicarious trauma in my practice of immigration law."

"I had a client erroneously put in expedited removal. We badgered ICE with release requests until my colleagues filed a successful habeas petition. That all felt like the normal fight. But a month later, I spent two days of advocating with multiple CBP and ICE offices to help him comply with a "check-in" with CBP only to have to tell the client that he was likely going to be re-detained. He broke down in tears on the phone. Even though we averted re-detention, the sound of helplessness in my client's voice stuck with me. The rest of the week, I found myself lacking motivation and feeling physically exhausted. I could not understand why, especially because we were successful! But I've come to realize that when individual clients confront unilateral, oppressive systemic policies that have little or no opportunity for redress that triggers me. I guess I feel like what good am I as an attorney if I am helpless against ICE, too?"

"I once represented a detained client diagnosed with paranoid schizophrenia in seeking asylum. The Immigration Judge first denied the case, and then I obtained a supplemental psychological evaluation, which resulted in the judge reopening the case and eventually granting asylum. The case was very emotionally taxing on me due to the individualized needs of the client and high demands of the complex legal case. I was thrilled to win the case 
and kept in touch with the client after his release from ICE detention, even going so far as giving him my cell phone number in case of emergency. A few months after his release, I learned that my client had passed away in a tragic car accident. I was shaken to my core. I tried to compartmentalize my emotions and didn't discuss it with my colleagues, staff, family, or friends. I buried my feelings and let the plight, struggles, and needs of my other clients fill in the void I was feeling, without truly addressing the grief head on."

These stories are consistent with documented negative trauma exposure responses including intrusive thoughts, hypervigilance, psychosomatic symptoms ranging from chronic exhaustion, headaches, and stomach aches to more severe ailments. ${ }^{19}$ Yet, while these negative trauma exposure responses are normalized in the literature, such responses are not uniformly normalized or accepted as natural responses among the immigration bar.

\section{Building Resilience Among the Immigration Bar}

Rather than deny or debate the existence of vicarious trauma symptoms, the immigration bar should instead focus on helping member attorneys engage in a practice of "trauma stewardship" and cultivating resilience. Author Laura van Dernoot Lipsky describes trauma stewardship as "a daily practice through which individuals, organizations, and societies tend to the hardship, pain, or trauma experienced by humans ... even the most urgent human and environmental conditions in a sustainable and intentional way." ${ }^{20}$ For immigration attorneys, this means cultivating a legal practice that allows us to engage diligently with our clients, while not "internalizing [client] struggles or assum[ing] them as our own" nor allowing our negative trauma exposure responses to affect our ability to competently provide representation, make our work unsustainable, or contribute to toxic or dysfunctional work culture. ${ }^{21}$ This section explores ways in which law schools, individual practitioners, and supervisors can build such resilience.

\section{Law School Education and Continuing Legal Education Seminars}

Law schools have started to recognize the need for students to reflect on and be in touch with their whole being as they transition to becoming lawyers. Mindfulness has made inroads into law school curriculums, with some schools offering meditation or mindfulness for lawyers courses for credit, or, in some instances, even making a mindfulness course a mandatory part of the first year curriculum..$^{22}$ Mindfulness and meditation can be just one of many tools in preventing and addressing symptoms of secondary trauma, but an explicit focus on the subject is lacking within most law schools. Clinical courses in 
which students provide representation to traumatized individuals do usually engage this topic, ${ }^{23}$ but insufficient attention and energy is typically devoted to a discussion of vicarious trauma.

Therefore, much can be done within law schools to increase trauma literacy and train trauma-informed, self-aware lawyers. The most logical place to start with reform is within experiential education; if a student finds her way into an immigration clinic, it is somewhat likely that the clinical instructors will include at least one class session on working with survivors of torture and trauma, which may include a component on vicarious trauma or self-care. In addition to this session, professors should weave discussions of trauma and vicarious trauma into the clinic curriculum. Additional steps may include:

- Discussing trauma and vicarious trauma in official clinic documents, including the syllabus and any articulation of learning objectives or goals; ${ }^{24}$

- Teaching specific classes focused not only on trauma-informed client representation but also addressing vicarious trauma and providing students with tools to self-assess within those classes; ${ }^{25}$

- Revisiting the topic during weekly supervision meetings or through reflection memos; ${ }^{26}$

- Administering various self-tests or quizzes to measure vicarious trauma and burnout; ${ }^{27}$

- Explicitly discussing trauma and vicarious trauma at the midsemester and final evaluation; ${ }^{28}$

- Periodically opening the clinic seminar class with a brief pulse check around the room-asking students to share one word about how they are feeling about their case work, about how they would describe their work-life balance or self-care, or other reflective prompts $;{ }^{29}$ and

- Incorporating a social worker or therapist into the clinic $^{30}$ or for specific clinic projects, ${ }^{31}$ or even creating a dual-disciplinary clinic incorporating social work students fully into the clinic. ${ }^{32}$ Cross-disciplinary and community partnerships are key. ${ }^{33}$

Immigration professors and supervisors within internships, externships, and job placement should also consider honestly and openly sharing their own trauma journey. Modeling how to address vicarious trauma and an admission that you as the "professor" or as the "lawyer" (or both) can be a powerful way to normalize discussions of trauma. One method of coping with vicarious trauma is to ensure adequate debriefing with colleagues and those within the zone of confidentiality associated with the particular client work at hand. If the supervising professor is able to share her own experiences, this can help open up discussions in groups or one-on-one with students who may also be experiencing symptoms of vicarious trauma. ${ }^{34}$ 
It is important to note that not all law schools have immigration clinics, and not all immigration lawyers will take a clinic, let alone an immigration clinic, before graduating law school. We must, therefore, look beyond the walls of the law school for more comprehensive solutions to address the gap in knowledge, awareness, and discussion of vicarious trauma. For example, in the context of continuing legal education (CLE) courses, bar associations and organizations conducting CLEs need to move beyond providing "self-care and trauma 101" trainings for attorneys attending such courses and seek to engage trauma stewardship as an ethical issue throughout legal education curricula.

Additionally, for legal aid organizations that regularly partner with pro bono attorneys, especially attorneys who conduct pro bono work from outside the immigration profession, there is a need for these attorneys to develop trauma stewardship skills as well. Training pro bono attorneys to engage in trauma stewardship not only will prevent negative trauma exposure responses from prejudicing clients during the course of the pro bono representation but may increase the likelihood that pro bono attorneys will continue to provide pro bono representation to immigrant clients.

\section{Trauma Stewardship by Individual Attorneys/Advocates}

For individual practitioners, developing a trauma stewardship practice involves both taking steps for vicarious trauma prevention and addressing symptoms when symptoms of vicarious trauma arise. The reality is that attorneys and legal staff engaged in direct representation of clients will suffer negative trauma exposure responses that may lead to instances, episodes, or seasons of vicarious trauma. This is not to say that practicing immigration law is a hopeless endeavor, but merely acknowledges that experiencing vicarious trauma over the course of one's career is normal. The goal of trauma stewardship is to develop awareness to mitigate these symptoms and prevent episodes of vicarious trauma that result in ethical violations, harm to clients, or transitions out of removal defense representation.

Discussing vicarious trauma prevention can devolve into a laundry list of "self-care" tips and techniques or "pop culture" notions of commoditized self-care. It is true that for all professionals, developing self-care practices around health and wellness (such as getting sufficient sleep, regular exercise, healthy eating habits, and having good practices regarding amount of screen time) is important. Certainly, prioritizing client work over engaging in these healthy behaviors can in and of itself be a symptom of vicarious trauma, such as when traumatized attorneys feel that they can never do enough or have an overinflated sense of the importance of legal representation to the point of developing a savior complex. However, wellness behaviors alone will not mitigate the long-term effects of vicarious trauma. Nor will "pop culture" notions of self-care, more appropriately characterized as self-soothing, which 
can range from getting manicures to spending time with therapy dogs. As attorney Bea Bischoff puts it, "all the self-care in the world won't change the fact that I work in a place and within a system in which asylum cases are granted only around 3 percent of the time.... It is hard to experience the relaxation promised by a lavender pillow mist when your clients are trapped in detention centers without access to proper hygiene or food." ${ }^{35}$ Rather, trauma stewardship is a set of client practice skills described below that all attorneys can cultivate and deepen over time.

\section{Trauma Time Management}

Attorneys engaged in trauma stewardship engage in time management in ways that acknowledge the risk of vicarious trauma. They may limit how many client meetings they conduct per day or how many fact-intensive affidavits they or their staff write with clients in a particular time frame. Attorneys should be mindful of how they respond when finishing filings, writing briefs, or doing trial preparation, and should take steps to de-escalate after long periods of writing or testimony preparation. This can take careful planning and awareness of work patterns to allow for sufficient time to monitor and feel emotions instead of pushing on to the next case or just burying emotions that may bubble to the surface at another (more inconvenient) time-or worse, that manifest while interacting with another client. Attorneys should also intentionally use their time off in ways that increase the sustainability of their advocacy. For some, that may mean taking one long vacation each year and completely going "off the grid," while for others it may be shorter vacation periods after large trials or intense cases. Beyond vacation, attorneys should also take sick days and mental health days and encourage colleagues and support staff to do the same.

\section{Set and Keep Client Boundaries}

While boundary setting is important for all attorneys to enable sustainable ethical practices, it may take different forms. Boundary setting ranges from deciding if and when you give out your cell phone number to clients to making exceptions for irregular meeting times to accommodate client schedules or needs outside business hours. However, working with clients who have experienced trauma or who may still be experiencing trauma may feel different from working with clients who have not. Monitoring responses and finding boundaries enable healthy relationships for both attorney and client. For example, if a client is experiencing a crisis or high level of distress, or is subject to constant levels of crisis by virtue of immigration detention or risks because of immigration status, finding ways to demonstrate empathy and being of assistance while still demarcating clear expectations is consistent with a trauma-informed, relationship-centered approach to legal representation. ${ }^{36}$ 


\section{Self-Monitor and Create a Personal Safety Plan}

Attorneys should develop habits of self-monitoring responses and behavior patterns based on their reactions to different client experiences. For instance, some attorneys may find themselves particularly triggered by testimony about domestic violence or targeting by law enforcement. Other advocates may find it is a client's current behavior or an emotional or indifferent response to the trauma that she suffered that activates their experience of secondary trauma. It is common for responses to ebb and flow over time, which may mean scheduling time annually or biannually to take a day or afternoon to attend to mental and emotional health, rather than addressing these issues only in crisis moments. Some individuals may even want to regularly complete the free professional quality of life scale compiled by the Center for Victims of Torture. $^{37}$

Every attorney should have a safety plan or vicarious stewardship toolbox of behaviors and activities they can access after moments of crisis or when feeling particularly triggered. These practices could include engaging in mindfulness techniques or breathing exercises, going to a place that feels calming or safe, engaging in physical activities specifically aimed at releasing any tension triggered by secondary trauma, or reaching out to a trusted colleague or attorney who may be able to cover a hearing or assist in a task without a long explanation or self-disclosure that may result in backlash.

Part of self-monitoring for attorneys is being aware of one's own background. Attorneys and advocates who themselves have suffered migrationrelated or other trauma in the past may also be triggered by certain client narratives, which in turn requires specific attention and management. This by no means suggests that immigrants are not outstanding, zealous advocates. Each individual attorney brings their own mix of experiences, privileges, strengths, and vulnerabilities to his or her work and may over time develop coping mechanisms that either mitigate or exacerbate vicarious trauma. However, self-awareness is key. Beyond self-monitoring, the immigration bar should also encourage attorneys to seek assistance from mental health professionals to assist in developing healthy coping mechanisms. Attorneys should also be mindful of the proclivity within the broader legal profession toward alcoholism and substance abuse and seek help from lawyer assistance programs offered by local bar associations.

\section{Cultivate a Support Team}

Practitioners should cultivate their own support team, from whom they may not only seek support but who they know will speak honestly and openly with them if their behavior changes. The most precarious situation is an attorney who has started to show symptoms of vicarious trauma that endangers ethical responsibilities but has not yet behaved in a way that has come to the attention of a disciplinary bar. ${ }^{38}$ In this situation, if an attorney 
does cross a line and violate ethical boundaries, other attorneys or community members may hesitate to speak up or confront the attorney, when in reality, such behavior if goes unchecked may escalate or create significant problems for the colleague and his or her clients. If an attorney becomes aware of her own symptoms of burnout, secondary trauma, compassion fatigue, or vicarious trauma that impede her ability to represent clients with reasonable diligence, promptness, and communication, the attorney should seek support from colleagues, support staff, friends, and family so that the attorney can meet their ethical requirements.

\section{Engage in Activism or Work Directly with Immigrant Communities}

Many attorneys may find that engaging in immigration-related political activism or efforts to make policy change-or, for attorneys whose day-today work is advocating for macro-level change, spending time engaging with clients and immigrant communities directly_may mitigate some symptoms of vicarious trauma, particularly symptoms of helplessness. ${ }^{39}$ Such activism may include participating in a community protest, engaging in an advocacy day organized by AILA or another immigration advocacy organization, contacting congressmen to advocate for immigration reform, or engaging with local community organizations. It may mean collaborating with clients and the press to widely publicize their plights or sharing advocacy experiences within professional or personal circles. It may also be powerful to visit immigrant neighborhoods where immigrants are engaging in day-to-day activities unrelated to their immigration case or to the systemic hardships that they endure. Connecting with immigrants outside of the power structure of a law office may help advocates perceive immigrants as survivors and not victims. However, an attorney should self-monitor to be aware of her own needs and boundaries; for some attorneys, the activities noted above may mitigate vicarious trauma, but for other attorneys, over-engagement or overexposure to immigration issues outside of the workplace may exacerbate symptoms of vicarious trauma. All attorneys need to engage in practices that work for them individually.

\section{The Role and Responsibility of Experienced Attorneys, Supervisors, and Bar Leaders}

Leaders and supervisory attorneys within law firms, nonprofits, and clinics have a responsibility to create safe spaces for trauma stewardship. For example, beyond advocating for policies such as vacation time, sick time, flex time, comp time, and mental health days, supervisors must actually encourage employees to use this time. Further, supervisors must work institutionally to ensure that mental health care is covered by any employer-provided healthcare plans. Less concrete but equally important steps include making efforts to acknowledge, 
address, and normalize vicarious trauma. As discussed above in the context of law schools and clinics, supervisors should model disclosure of vicarious trauma and explore ways to open the door to conversations with junior staff. It is important to offer training to new staff and consistently raise the topic of vicarious trauma throughout an employee's tenure. Further, supervisors must take care to avoid creating a culture where new or junior staff feel they are expected to show that they are "tough" or unaffected by trauma. Supervisors must make clear that showing emotions and empathy is valuable, but oftentimes takes a toll on the individual. Supervisors must strike a balance and ensure that vicarious trauma symptoms are neither penalized nor ignored but are instead acknowledged and mitigated.

\section{Conclusion}

This article is intended to ignite conversation among attorneys, law students, law professors, supervisors, and leaders in immigration law on the pervasiveness of vicarious trauma within the field, the barriers to preventing and addressing vicarious trauma, and the ethical imperative to do so effectively. However, further research and discussion is needed. In February 2020, one of the authors, Lindsay Harris, launched a national survey of immigration attorneys handling asylum cases to measure levels of burnout, stress, and vicarious trauma. ${ }^{40}$ The purpose of this survey is to gather additional data on best practices to train practicing immigration attorneys and build resilience in their current practices. In addition, more research is needed on the effects of re-traumatization on immigrants seeking relief through the immigration legal process in order to better train immigration attorneys on how to mitigate re-traumatization and vicarious trauma experienced by counsel and legal staff.

\section{Notes}

* Hannah C. Cartwright (hannah@mariposalegal.org) is Executive Director and attorney at Mariposa Legal in Indianapolis, Indiana, which is a program of COMMON Foundation, a 501(c)(3) not-for-profit organization. Lindsay M. Harris (lindsay.harris@ udc.edu) is an Associate Professor of Law and Co-Director of the Immigration and Human Rights Clinic at the University of the District of Columbia David A. Clarke School of Law. Liana E. Montecinos (lmontecinos@benachcollopy.com) is a Honduran asylee who became an attorney. She is an Associate Attorney at Benach Collopy, LLP, in Washington D.C., where she represents clients in immigration court, before Immigration \& Customs Enforcement (ICE), the U.S. Citizenship and Immigration Services (USCIS), and the Department of State (DOS). Anam Rahman (anam@calderonseguin. com) is a partner with Calderón Seguin, PLC in Fairfax, VA. She is also an Adjunct Professor of Law at Georgetown Law School, co-teaching a fieldwork practicum entitled Women and Immigration. Although Anam's immigration practice covers a broad array 
of matters, she specializes in removal defense and regularly practices before the Arlington and Baltimore Immigration Courts.

1. Denise Michultka, "Mental Health Issues in New Immigrant Communities," in Fernando Chang Muy, Social Work with Immigrants and Refugees: Legal Issues, Clinical Skills, and Advocacy $\$ 145-146$ (2009), quoting John Orley, "Psychological Disorders among refugees: some clinical and epidemiological considerations," Amidst Peril and Pain: The Mental Health and Well-Being of the World's Refugees (1994).

2. Marjorie A. Silver, Sanford Portnoy \& Jean Koh Peters, Stress, Burnout, Vicarious Trauma, and Other Emotional Realities in the Lawyer/Client Relationship: A Panel Discussion, 19 Touro L. Rev. 847, 860 (2004).

3. Jason M. Newell \& Gordon A. MacNeil, Professional Burnout, Vicarious Trauma, Secondary Traumatic Stress, and Compassion Fatigue: A Review of Theoretical Terms, Risk Factors, and Preventive Methods for Clinicians and Researchers, 6 Best Practice IN Mental Health 2, 57-68 (2010).

4. Id. at 60 .

5. Id. at 61 .

6. Id. at 60 .

7. Id.

8. Laura van Dernoot Lipsky \& Connie Burk. Trauma Stewardship: An Everyday Guide to Caring for Self While Caring for Others, $\$ 41-112$ (2009).

9. Id.

10. See, e.g., Lynette M. Parker, Increasing Law Students' Effectiveness When Representing Traumatized Clients: A Case Study of the Katharine \& George Alexander Community Law Center, 21 Geo. Immigr. L.J. 163, 177-80 (2007); Jean Koh Peters, Representing Children in Child Protective Proceedings, 467 (2007) ("[B]oth the duty to contain our counter-transference in any individual case, and the duty to address our vicarious traumatization as the overall context of our ongoing work for all of our clients, are ethical imperatives.").

11. Parker, supra, 177-79, n.67.

12. See, e.g., Bryant, Susan, Five Habits: Building Cross-Cultural Competence in Lawyers. 8 Clinical L. Rev. 33-107 (2001).

13. See, e.g., Hannah Cartwright, Gregory Pleasants \& Megan Hope, Self-Care in an Interprofessional Setting Providing Services to Detained Immigrants with Serious Mental Health Conditions, 65 Social Work 1 (2020).

14. Van Dernoot Lipsky \& Burk, supra note 8.

15. Id. at 81 .

16. Id. at 151-55 (profiling the Northwest Immigrant Rights Project and the decision by the leadership to shut down intake during a particularly untenable period experienced by the NWIRP staff).

17. The Center for Victims of Torture, Vicarious Traumatization (2018), https:// www.proqol.org/uploads/VT_Handout_3.2018.pdf.

18. Silver, Portnoy \& Peters, supra note 2 at 869.

19. Van Dernoot Lipsky \& Burk, supra note $8 \$ 41-112$.

20. Van Dernoot Lipsky \& Burk, supra note $8 \$ 11$.

21. Id.

22. See, e.g., Tim Iglesias, Offering and Teaching Mindfulness in Law Schools, 49 University of San Francisco L. Rev. Forum 24 (2015). 
23. See, e.g., Lynette M. Parker, Increasing Law Students' Effectiveness When Representing Traumatized Clients: A Case Study of the Katharine \& George Alexander Community Law Center, 21 Geo. Immigr. L.J. 163 (2007) (discussing the need for specialized training of law students working with survivors of trauma); Carol M. Suzuki, Unpacking Pandora's Box: Innovative Techniques for Effectively Counseling Asylum Applicants Suffering from Post-Traumatic Stress Disorder, 4 Hastings Race \& Poverty L.J. 235 (2007) (discussing PTSD and sharing techniques for attorneys to help an asylum seeker suffering with PTSD to tell a credible, consistent, detailed story); Julie M. Marzouk, Ethical and Effective Representation of Unaccompanied Minors in Domestic Violence-Based Asylum Cases, 22 Cuinical L. Rev. 395, 399 (2016) (focus on training law students to ethically represent children survivors of trauma avoiding re-traumatization as much as possible); Sarah Katz \& Deeya Haldar, The Pedagogy of Trauma-Informed Lawyering, 22 CLINICAL L. Rev. 359, 363 (2016) (recognizing the four key components of trauma-informed lawyering as identifying trauma, adjusting the lawyer-client relationship, adapting litigation strategy, and preventing vicarious trauma).

24. The Syllabus for the Columbia Law School Immigrants' Rights Clinic, for example, specifies the following goals: "Learn how to engage in challenging work on a sustained basis; Develop an ability to maximize your compassion satisfaction and reduce burnout; Be mindful of secondary traumatic stress." See email on file with authors from Elora Mukherjee.

25. For example, within the University of the District of Columbia (UDC) Law Immigration and Human Rights Clinic we use the "Fill Your Life Well" exercise adapted from an exercise shared by Liala Buoniconti, social worker with Harvard's Immigration and Refugee Clinical Program. Students complete a worksheet to reflect which activities "drain" their well of energy and which "refill" the well. We then share, as a group, as much as students are willing, and revisit the well-draining and filling concept throughout the semester.

26. The University of Baltimore's Immigrant Rights Clinic assigns a reflection memo specifically on the topic of self-care and vicarious trauma. See email on file with authors from Nickole Miller.

27. A variety of different tools are currently used including, for example, the ProQOL, Center for Victims of Torture. Developed by B. Hudnall Stamm, Professional Quality of Life: Compassion Satisfaction and Fatigue Version 5 (ProQOL) (2009-2012), https://www.proqol.org/uploads/ProQOL_5_English_Self-Score_3-2012.pdf. The ProQOL is used within Harvard's Immigration and Refugee Clinical Program. See Email on file with author from Sabrineh Ardalan and within the Columbia Immigrant Rights' Clinic. See email on file with authors from Elora Mukherjee. The Seattle University Gender Violence Immigration Clinic, for example, administers a stress assessment and a self-care assessment. See email on file with authors from Monika Bashra Kashyap.

28. At the Northwestern Immigrant Justice Clinic, for example, Hemanth C. Gundavaram reports that the students take a self-care assessment around a month into the semester and revisit throughout, including at the mid-semester stage and during their exit interview.

29. We frequently use this tool in the Immigration and Human Rights Clinic at the UDC Law School and find that it helps to inform the direction we need to be taking to support students throughout the semester.

30. See, e.g., Sabrineh Ardalan, Constructive or Counterproductive? Benefits and Challenges of Integrating Mental Health Professionals into Asylum Representation, 30 GeO. 
IMMigR. L.J. 1 (2015). Boston University's Immigrants' Rights and Human Trafficking program has established a partnership with the school of social work through which office hours and other support is offered to students. See email on file with authors from Sarah Sherman Stokes. The University of Tulsa's clinical program has partnered with a psychology professor who specializes in trauma and vicarious trauma. See email on file with authors from Mimi Marton.

31. See, e.g., Lindsay M. Harris, Learning in Baby Jail: Lessons Learning from Law Student Engagement in Family Detention Centers, 25 Clinical L. Rev. 155, 172, 207, 215 (2018) (discussing partnerships with social workers for clinics engaged in intensive fieldwork within family detention centers, including traveling with a social worker as part of the team).

32. Jacqueline St. Joan, Building Bridges, Building Walls: Collaboration Between Lawyers and Social Workers in a Domestic Violence Clinic and Issues of Client Confidentiality. 7 Clinical L. Rev. 403 (2001).

33. For example, the Center for the Human Rights of Children (CHRC) at Loyola University Chicago, School of Law, has established materials to address vicarious trauma for their new Immigration Law Practicum through partnerships with the Illinois Child Trauma Coalition, Refugee and Immigrant subcommittee, and faculty partners within the University's Psychology Department. See email on file with authors from Katherine Kaufka Walts. At Tulane University within the immigration practicum, Professor Laila Hlass has partnered with a social worker to create an exercise to assist with issue spotting trauma and vicarious trauma issues. See email on file with authors from Laila L. Hlass.

34. Lindsay Muir Harris, An Open Book? Self-Disclosure in Clinical Teaching, Clinical Law Prof. Blog (Nov. 17, 2017), https://lawprofessors.typepad.com/ clinic_prof/2017/11/an-open-book-self-disclosure-in-clinical-teaching.html.

35. Bea Bischoff, I'm an Immigration Attorney in Trump's America and the Stress Took Over My Life, The Huffington Post (Jan. 8, 2019), https://www.huffpost.com/entry/ immigration-attorney-compassion-fatigue_n_5c33a4fde4b01b7197a2dcb3.

36. University of Buffalo Center for Social Research, What Is Trauma-Informed Care?, http://socialwork.buffalo.edu/social-research/institutes-centers/institute-ontrauma-and-trauma-informed-care/what-is-trauma-informed-care.html; Substance Abuse and Mental Health Services Administration (SAMHSA). SAMSHA's Concept of Trauma and Guidance for Trauma-Informed Approach. U.S. Department of Health and Human Services (2014), https://store.samhsa.gov/system/files/sma14-4884.pdf; see supra Katz \& Haldar note 23; see supra Cartwright, Pleasants \& Hope note 13.

37. See supra, n.27.

38. Christina Rainville, Understanding Secondary Trauma: A Guide for Lawyers Working with ChildVictims, AMERICAN BAR AssociaTion, https://www.americanbar.org/groups/pub lic_interest/child_law/resources/child_law_practiceonline/child_law_practice/vol-34/ september-2015/understanding-secondary-trauma--a-guide-for-lawyers-working-with/.

39. Rebecca Raney, Compassion Fatigue: A Side Effect of the Immigration Crisis, American Psychological Association (Oct. 15, 2019), https://www.apa.org/mem bers/content/compassion-fatigue?fbclid=IwAR0sT-xJjU3XIIfS98yY0smsjJF_DWYC0b9KczXiwCshGWMuLX50M8j61c.

40. Survey can be accessed at https://www.aila.org/about/announcements/ participate-in-an-asylum-attorney-burnout-stress?utm_source=Recent $\% 20$ Postings $\% 20$ Alert\&utm_medium=Email\&utm_campaign=RP\%20Daily. 